\title{
Evaluation of restoration effectiveness: community response to the removal of alien plants
}

\author{
Ruben Heleno, ${ }^{1,2}$ Inês Lacerda, ${ }^{2}$ Jaime A. Ramos, ${ }^{2}$ and Jane Memmott ${ }^{1,3}$ \\ ${ }^{1}$ School of Biological Sciences, University of Bristol, Bristol BS8 1UG, United Kingdom \\ ${ }^{2}$ Institute of Marine Research (IMAR/CMA), Department of Life Sciences, University of Coimbra, 3004-517 Coimbra, Portugal
}

\begin{abstract}
Plant invasions are a key cause of biodiversity loss and motivate many restoration programs worldwide. We assessed restoration success of an invaded forest in the Azores using two complementary experimental designs: a before-after control-impact (BACI) design compared a restored and a control (unmanipulated) site over three years, while a control-impact (CI) design evaluated the short-term effects of restoration on restored-control replicated pairs. In both designs, a food web approach was used to evaluate both structural and functional aspects of the restoration. Two years after removing alien plants from the BACI design, there were increases in the abundance of native seeds $(110 \%)$, herbivorous insects (85\%), insect parasitoids (5\%), and birds (7\%) in the experimental plot compared to the unmanipulated plot. In the CI design, five experimental plots were weeded and paired with five adjacent unmanipulated plots. Immediately following the removal of alien plants within the experimental plots, there was a significant decrease in native plant species, likely attributed to the effect of disturbance. Nevertheless, the production of native seeds increased by $35 \%$ in year 1 , and seed production of the focal endemic plant, Ilex perado (holly), increased $159 \%$ in year 2. Weeding increased the survivorship and growth of seedlings transplanted into the plots, particularly those of alien species. Both experiments provide evidence of the positive effects of weeding cascading through the food web from native plants to herbivorous insects, insect parasitoids, and birds. Two aspects that could prove critical to the outcome of restoration programs deserve further attention: most bird-dispersed seeds were alien, and weeding favored alien over native seedling growth.
\end{abstract}

Key words: Azores; Azores Bullfinch; BACI; before-after control-impact; biological invasion; food web; habitat restoration; laurel forest; management; Pyrrhula murina.

\section{INTRODUCTION}

Nonnative invasive species frequently have a negative impact upon the communities they invade (Wilcove et al. 1998, Mack et al. 2000). This impact can be seen as increased competition with native species for resources (e.g., Woods 1993), alteration of habitat structure (e.g., Scheiman et al. 2003), changes in nutrient cycling (e.g., Vitousek et al. 1987), or the disruption of native food webs (e.g., Henneman and Memmott 2001) and mutualistic webs (e.g., Traveset and Richardson 2006). Given the increasing prevalence of alien species worldwide (D'Antonio and Chambers 2006), restoration ecologists are frequently faced with the challenge of managing invaded ecosystems (Vander Zanden et al. 2006, Forup et al. 2008). However, because most key issues in invasion biology fall squarely at the community level (Simberloff 2004), and community assembly rules lay at the very foundation of restoration ecology (Palmer et al. 1997), restoration after invasion cannot

Manuscript received 4 August 2009; accepted 23 September 2009; final version received 28 October 2009. Corresponding Editor: E. A. Newell.

${ }^{3}$ Corresponding author.

E-mail: Jane.Memmott@bris.ac.uk be accurately monitored by focusing on one or a few components of biodiversity (Temperton et al. 2004). Our aim here is to assess the success of habitat restoration, over a three-year period, using a community-level approach, where we consider the plant community, the herbivorous insects, the granivorous and frugivorous birds feeding on the plants, and the parasitoids feeding on the herbivores. We based our study in the native forests of the Azores, which are severely affected by plant invasions and the subject of a large-scale restoration program. Our approach contrasts with the manner in which previous studies have traditionally been conducted, where the focus has been upon changes observed within a single species or trophic level, usually plants. Such approaches are likely to prove unsatisfactory for restoration practitioners who need to manage ecosystems as a whole. Our community-oriented approach increases the monitoring demands for restoration projects, but it addresses restoration from a holistic viewpoint, rather than a species-centric one.

Two complementary experimental designs were used: a before-after control-impact (BACI) design followed the recovery of a large weeded plot and a matched unmanipulated plot over three years, while a controlimpact (CI) design looked at the effects of weeding on 
paired weeded and unmanaged plots over one year. We considered the effect of alien plant removal on five structural and functional aspects of the community: seed production, seed consumers, seed dispersal, network structure, and seedling survival and growth. The two designs are complementary, as they focus on different aspects of the response of a community to alien plants. While the BACI approach focused on the medium-term effects and considered temporal variability, the CI approach focused on short-term effects and considered spatial variability. With regard to current knowledge concerning the impacts of alien species on native communities, our predictions concerning the likely outcome of weed removal on our five structural and functional aspects are as follows.

1) Effect on seed production. Alien and native plants compete for resources such as space, light, water, nutrients, and mutualistic partners (Woods 1993, Lopezaraiza-Mikel et al. 2007). Therefore, we predict that releasing native plants from the competition of aliens will increase their access to resources and have a positive effect on native seed diversity and abundance.

2) Effect on seed consumers. Alien plants usually lack specialist enemies in their exotic range, and generalist herbivores are predicted to have a greater effect on the native flora than on alien species (enemy release hypothesis, reviewed by Keane and Crawley 2002). Herbivore insect biomass decreases during alien plant invasion (Heleno et al. 2009); here we predict the opposite when alien plants are removed. Thus the predicted increase in native seed production will increase resources available for seed-feeding insects and thereby increase their diversity and abundance (and consequently their biomass). As a consequence of this, we expect an increase in the abundance and diversity of parasitoids feeding on the seed-feeding insects. Finally, we expect an increase in the abundance of frugivorous and granivorous birds as a consequence of the enhanced native seed/ fruit production. This expectation is based on the diet of most birds, which includes a larger fraction of native seeds and fruits (Ramos 1996, Heleno et al. 2009). This scenario is particularly likely for the critically endangered Azores Bullfinch (Pyrrhula murina; IUCN 2005), which is largely dependent on native food sources (Ramos 1995).

3) Effect on seed dispersal. Even if restoration results in the recovery of species richness, this does not guarantee that the processes in which those species are involved have been reestablished (Palmer et al. 1997, Forup et al. 2008). Seed dispersal is one of these processes and one that to a great extent determines vegetation structure (Wang and Smith 2002), such that the incomplete restoration of such an important ecosystem service may result in a community failing to be self-sustaining (Henson 2007). Here we assess whether the predicted increase in frugivorous birds effectively translates into the restoration of seed dispersal.
4) Effect on network structure. Understanding the impact of alien plants on the interactions between species is important, as these can be significantly affected by habitat modification without any obvious change in widely used measures of biodiversity (Tylianakis et al. 2007). It is now recognized that species interactions are key attributes of successfully restored systems and should be part of evaluation protocols (Menninger and Palmer 2006). Considering the overall network of interactions that includes the trophic relationship between seeds, herbivores, and parasitoids (i.e., food web) and the mutualistic interactions between birds and seeds (i.e., seed dispersal web), we make the following predictions: (a) the number of links (i.e., interactions) will decrease initially as all the interactions with alien plants are removed and increase in the following years as a consequence of a diversification of native plants and insects; (b) connectance (the proportion of possible links that are realized) will decrease as generalist herbivores feeding on alien seeds are replaced by more specialized ones feeding on native seeds; and (c) interaction evenness (uniformity of link distribution) will increase as a species-poor alien vegetation is replaced by a more diverse native flora.

5) Effect on seedling survival and growth. Weeding increases the amount of light that reaches the understory and creates areas of newly disturbed ground, which benefits species that rapidly take advantage of abundant resources (Mack et al. 2000, Shea and Chesson 2002). It has been suggested that alien plants are particularly successful at exploring resource-rich environments (Davis et al. 2000, Daehler 2003). Given an increase in available resources after weeding, we predict that alien seedlings will grow more vigorously than co-occurring natives.

\section{Methods}

\section{Field site and the restoration project}

The Azores archipelago is composed of nine islands located along the mid-Atlantic ridge. Its extreme isolation, its richness in endemic taxa, and the recent spread of invasive plants that threaten native habitats makes it an ideal field site for studying plant invasions (Ramos 1996, Silva 2001). The Azores are characterized by a temperate oceanic climate with high relative humidity, small temperature range, and considerable rainfall throughout the year, particularly from September to April (Silva and Smith 2006; see also Appendix A). This study was conducted in São Miguel $\left(37^{\circ} 47^{\prime} \mathrm{N}, 25^{\circ} 29^{\prime} \mathrm{W}\right)$, the largest island of the archipelago, about $1300 \mathrm{~km}$ west of the Portuguese coast. Mean annual temperature in the study area is $14^{\circ} \mathrm{C}$, and mean annual precipitation is $1900 \mathrm{~mm}$ (University of the Azores, Angra do Heroísmo Azores, Portugal; data available online). ${ }^{4}$ Native vegetation in

\footnotetext{
${ }^{4}\langle$ www.climaat.angra.uac.pt $\rangle$
} 
the east of São Miguel has largely been cleared for pastures, planted with a production forest of Cryptomeria japonica (Japanese red cedar), or taken over by weeds (Ramos 1995, Silva 2001). The remnant native forest (the laurel forest) hosts species of particular conservation interest; for example, eight tree species within the laurel forest are endemic, along with the Azores Bullfinch and the endemic Azores bat (Nyctalus azoreum) (International Union for Conservation of Nature [IUCN] 2000). Within the native forest, the endemic tree Ilex perado (holly) is an important species for at least three reasons: (1) through its abundance and structural diversity it provides a major component of the Azorean cloud forest (Tutin 1953, Haggar 1988); (2) it is an important host for native seed herbivores and their parasitoids (Heleno et al. 2009); and (3) its flower buds are an essential food source for the Azores Bullfinch in early spring, a period when food is otherwise scarce (Ramos 1995). Given the vulnerability of the last population of the Azores Bullfinch, greatly threatened by invasive species, the Portuguese Society for the Study of Birds (SPEA) launched a restoration project entitled "Recovery of Azores Bullfinch's habitat in the Special Protection Area of Pico da Vara/Ribeira do Guilherme." With funding of over three million euros, the project's main aim was to recover 300 hectares of the Azores Bullfinch's habitat from exotic plant invasion (information available online). ${ }^{5}$

The method used to remove alien plants from our experimental plots followed those used by SPEA in the restoration program. This involved removing manually and chemically four weed species (Pittosporum undulatum, Hedychium gardneranum, Clethra arborea, and Acacia melanoxylon) from the experimental plots. Alien plants were felled by machete and the stump sprayed with herbicide (Ally [metsulfuron methyl; DuPont, Wilmington, Delaware, USA] at 20\%). Felled vegetation was used to cover the managed area to prevent leaching. On trees, strategic cuts were made low on the trunk, and they were sprayed with herbicide and left to die standing. In the before-after control-impact (BACI) design, we worked within the ongoing restoration efforts, and in the control-impact (CI) design, the restoration team accommodated our design within their restoration efforts. We used these two complementary experimental designs to study the recovery of plots after alien plant eradication.

\section{The BACI design}

Here we followed the recovery of a four trophic-level food web, linking seeds, their insect herbivores, parasitoids of the herbivores, and birds over three years within an experimental and an unmanipulated plot. The experimental plot was $70 \times 140 \mathrm{~m}$ (approximately 1 ha) and at the start of sampling consisted of mature

\footnotetext{
5 Wwww.spea.pt/ms_priolo $\rangle$
}

native forest highly invaded by $H$. gardneranum, $C$. arborea, and A. melanoxylon (see Appendix B for initial composition of both plots). The unmanipulated plot $(100 \times 100 \mathrm{~m})$ consisted of uninvaded mature native forest where the only exotic species was Leicesteria formosa, which made up $<2 \%$ of all seeds produced. The experimental plot was sampled from June to November in 2005, covering the fruiting period of the majority of plant species present (Schäffer 2002; unpublished data). Alien plant eradication in the experimental plot was carried out on a single occasion during the winter of 2005, and this plot was resampled during the same period and with equal effort in both 2006 and 2007. The unmanipulated plot was sampled from July to September in 2005 and 2007. The two plots were 1.5 $\mathrm{km}$ apart, with the experimental plot at $500 \mathrm{~m}$ above sea level (a.s.1.) and the unmanipulated plot at $700 \mathrm{~m}$ a.s.1., because suitable pristine plots to use as an unmanipulated control did not occur at $500 \mathrm{~m}$ a.s.l. Given that diversity is expected to decrease with altitude (e.g., MacArthur 1972), the unmanipulated plot in this study is not a classic reference plot representing the ultimate goal of an effective restoration. Rather, if restoration is successful, we expect the biodiversity in our experimental plot to exceed that in the unmanipulated plot, as it is at lower elevation. Thus the role of our unmanipulated plot is to serve as a benchmark for the natural development of the vegetation in an undisturbed site (Osenberg et al. 2006). Hereafter within the BACI design, 2005, 2006, and 2007 will be referred to as year 0 , year 1 , and year 2, respectively.

Seed sampling.- Seeds were sampled every three weeks along 100-m linear transects. Ten transects were sampled each year in the experimental plot and three in the unmanipulated plot. In both designs, transects were parallel and transect order was randomly chosen. Along transects, all ripe seeds and fruits (hereafter collectively referred to as seeds) within $1 \mathrm{~m}$ of the transect line were collected from the plants, identified, and counted (see Plate 1). Where the collection of all seeds from a species in a transect was impractical due to their high abundance, they were subsampled and the results extrapolated for analysis. These provided quantified information on seed species richness, abundance, and evenness. Throughout the study, plant and insect taxonomy follows Borges et al. (2005).

Insect sampling.- Seeds collected from transects were placed inside 1-mm microperforated polypropylene bags $(10 \times 15 \mathrm{~cm})$ to rear all herbivores and parasitoids. Bags were inspected every four days for a period of 10 weeks. Insect exit holes present on seeds were recorded and considered to be evidence that an herbivore had emerged prior to seed collection. Herbivores and parasitoids that emerged during this period were identified by taxonomists. These rearings provided data on herbivore and parasitoid species richness and abundance. Where the collection of all seeds of a single species present within a single transect was not practical due to high abundance, these seeds were subsampled and multiplied up prior to 
analysis. Insect abundance was defined as the total number of insects reared, their biomass being the cumulative weight estimated from insect length using the body length to body mass conversion equations developed by Sample et al. (1993).

Bird sampling.-Bird density was estimated using 8 min long point counts, starting 1 min after arrival at the census point (Bibby et al. 2000). Two fixed census points with good visibility were chosen inside each plot and sampled alternately. Four point counts were carried out every three-week period over two days at 8:00 and 9:00 hours. Birds were recorded as being inside or outside the plot according to the place where they were first seen or heard. The data from the two daily censuses were combined, such that for each bird species, the maximum number of individuals detected inside the plot during either census was divided by plot area to estimate bird density. Given that all forest birds in the Azores are resident (Ceia et al. 2009), the density of each species was averaged for all periods at each plot and for all plots in order to estimate overall bird density.

Building the networks and quantifying network structure.-

1. Seed dispersal network.-Bird diet was assessed by collecting fecal samples of mist-netted birds. Two mistnetting sessions ( $5 \mathrm{hr}$ each, starting at sunrise) were performed every three weeks in the experimental and unmanipulated plots. Captured birds were kept inside calico bags to defecate for a maximum of 30 minutes, and droppings were stored in $70 \%$ ethanol for later analysis. Entire seeds in the droppings were identified under a dissecting microscope using seed reference collections. The results are presented in terms of the proportion of droppings that contained at least one whole seed of each species. Whole seeds that were found in droppings but not present in any seed transects within that specific plot (i.e., species whose immigration to the plot is being assisted by birds) were referred to as "new seeds."

2. Plant-herbivore-parasitoid networks.-Using the rearing records, networks were constructed that showed the feeding relationships between plants, herbivores, and parasitoids.

3. Visualizing and analyzing the networks.-Networks were visualized using a program written in Mathematica 4.0 (Wolfram Research 1999), based on a matrix that quantifies the frequency of interactions between each prey-predator pair. Species were classified as top, intermediate, or basal according to their relative position in the food web. Top species have prey but not consumers; intermediate species have both prey and consumers; basal species have consumers but not prey (e.g., Sugihara et al. 1989, Bersier et al. 2002, Dunne et al. 2004). Additionally, we considered a basal species to be any plant whose seeds or fruits were collected even if no herbivores emerged; i.e., plant species did not have to be linked to other species to be considered part of the food web. While this increases the number of basal species and thereby reduces connectance, it provides a more realistic picture of the community (Heleno et al. 2009).

The level of detail from each of the two plots comes at the expense of reduced statistical power, a recurrent problem in restoration studies (Osenberg et al. 2006). Consequently, the results of this experiment are presented in terms of the direction and magnitude of the response in the experimental plot compared with the unmanipulated plot rather than according to statistical outputs.

\section{The CI design}

In the CI approach, 10 plots, $50 \times 50 \mathrm{~m}$ in size, were established in invaded areas of the laurel forest (altitude $500 \mathrm{~m}$ a.s.1.) using a paired design, with the plots from each pair being adjacent. While the five pairs differed in the level of invasion and initial floral composition, these were consistent within a pair (Appendix C). As in the BACI design, the unmanipulated plots in the CI design do not represent the ultimate goal for restoration; rather they serve as a control with which to compare the experimental plots. The experimental plots were weeded in the winter of 2006 (year 0 in the CI design), and sampled monthly for their seeds, herbivorous insects, and parasitoids between May and November 2007 (year 1 in the CI design). As in the BACI design, alien plant removal was done only once.

Seed sampling.- Seeds were sampled monthly in the 10 plots in year 1 using 50-m linear transects, yielding seven transects per plot over the sampling season, with plots in the same pair being sampled on the same day. In year 2, I. perado was chosen as a focal species for assessing the impact of weeding on seed production in the CI experiment. Thus in July 2008 (year 2), berries were counted on all $I$. perado trees within each plot. In addition, the diameter at breast height (DBH) of each $I$. perado tree was measured. A univariate general linear model (GLM) was used to assess the effect of weed removal treatment on the number of $I$. perado fruits produced $(\log (x+1)$-transformed) with DBH as a covariate (Grafen and Hails 2002).

Insect sampling.-Insects were reared from seeds collected along transects as in the BACI design. The effect of weeding on plants and insects under the CI design was assessed using a repeated-measures GLM with plot pairs as subjects (Grafen and Hails 2002). Because the magnitude and variability of the effects are often more informative in the evaluation of restoration (Osenberg et al. 2006), the results are presented and discussed in terms of the percentage change $(\% \Delta)$ between experimental (i.e., restored) and unmanipulated sites.

Seedling survival and growth.-Young plants $(5-8 \mathrm{~cm}$ in height, hereafter referred to as seedlings) were collected locally and transplanted, on the same day, to the center of each paired plot under the CI design. Three seedlings of nine common species (four aliens, $P$. undulatum, H. gardneranum, C. arborea, and Leicesteria formosa; and five natives, I. perado, Vaccinium cylindraceum, Viburnum tinus, Erica azorica, 
TABLE 1. Comparison of community descriptors between the two plots (1 ha) under the before-after control-impact (BACI) design.

\begin{tabular}{|c|c|c|c|c|c|c|}
\hline \multirow[b]{2}{*}{ Descriptor } & \multicolumn{3}{|c|}{ Experimental } & \multicolumn{3}{|c|}{ Unmanipulated } \\
\hline & Year 0 & Year 1 & Year 2 & Year 0 & Year 1 & Year 2 \\
\hline \multicolumn{7}{|l|}{ Seeds } \\
\hline Alien diversity & 2 & 4 & 9 & 7 & & 7 \\
\hline Native diversity & 10 & 14 & 21 & 18 & & 22 \\
\hline Alien abundance & 14263 & 414 & 704 & 749 & & 4886 \\
\hline Native abundance & 41055 & 50948 & 96213 & 31419 & & 33259 \\
\hline Evenness & 0.645 & 0.423 & 0.518 & 0.575 & & 0.59 \\
\hline Percentage alien seeds & 25.8 & 0.8 & 0.7 & 2.3 & & 12.8 \\
\hline \multicolumn{7}{|l|}{ Insects } \\
\hline Herbivore diversity & 9 & 6 & 11 & 5 & & 8 \\
\hline Herbivore abundance & 5745 & 5198 & 10640 & 2862 & & 1457 \\
\hline Parasitoid diversity & 2 & 2 & 2 & 1 & & 1 \\
\hline Parasitoid abundance & 1346 & 3 & 1407 & 3 & & 36 \\
\hline Diversity & 11 & 8 & 13 & 6 & & 9 \\
\hline Abundance & 7091 & 5201 & 12047 & 2865 & & 1493 \\
\hline Biomass (mg) & 4407 & 3564 & 13723 & 1324 & & 977 \\
\hline \multicolumn{7}{|l|}{ Birds } \\
\hline Diversity & 9 & 9 & 9 & 9 & & 9 \\
\hline Density (birds/ha) & 14.8 & 14.8 & 15.9 & 12 & & 10.8 \\
\hline Alien abundance & 17 & 18 & 41 & 2 & & 8 \\
\hline Native abundance & 34 & 56 & 38 & 5 & & 10 \\
\hline Alien diversity & 5 & 4 & 4 & 1 & & 1 \\
\hline Native diversity & 9 & 10 & 5 & 2 & & 4 \\
\hline New aliens dispersed in & 5 & 4 & 2 & 1 & & 0 \\
\hline New natives dispersed in & 4 & 3 & 1 & 0 & & 0 \\
\hline \multicolumn{7}{|l|}{ Network } \\
\hline Species diversity (total) & 41 & 42 & 55 & 41 & & 47 \\
\hline Number of trophic links & 18 & 12 & 18 & 11 & & 12 \\
\hline Number of mutualistic links & 19 & 19 & 11 & 3 & & 7 \\
\hline Link density (links/species) & 1.294 & 1.605 & 1.128 & 1.368 & & 1.934 \\
\hline Connectance & 0.056 & 0.059 & 0.026 & 0.044 & & 0.051 \\
\hline Interaction evenness & 0.513 & 0.421 & 0.464 & 0.525 & & 0.756 \\
\hline
\end{tabular}

Notes: In the experimental plot alien plants have been removed after year 0 ; the unmanipulated plot was maintained as a control throughout the three years but was not sampled in year 1. "Abundance" refers to the number of individuals (seeds, herbivores, or parasitoids); "diversity" refers to the number of species (species richness); and "new aliens/natives dispersed in" refers to the number of new alien/native species found dispersing into the plots. For explanation of the network variables see the Introduction.

and Lysimachia azorica) were planted in each trial, yielding a total of 270 plants $(3$ seedlings $\times 9$ species $\times 10$ plots). All plants were marked and their height measured when planting out in year 1 of the CI design, and one year later. Changes in the survival probability of native and alien plants were analyzed using binary logistic regression, including treatment, status, and species as covariates (Zar 1999, Dytham 2003). The effect of management on seedling height $(\log (x+1)$-transformed) was analyzed with a GLM (Grafen and Hails 2002). At the end of the experiment, all alien seedlings were removed from the plots and destroyed.

Building the networks and quantifying network structure.-The plant-herbivore-parasitoid networks were built and visualized as described in the BACI experiment. The effect of weeding on these network descriptors (number of links, link density, connectance, and interaction evenness) was explored via a repeatedmeasures GLM (Grafen and Hails 2002). Because food web descriptors are to some extent dependent on the size of the network (Bersier and Sugihara 1997), species richness was included as a covariate in the model.

\section{RESUlts}

The number of alien seeds in the weeded plots for both the control-impact (CI) and before-after controlimpact (BACI) designs was negligible $(0.1 \%$ and $0.8 \%$, respectively), indicating highly effective eradication of exotic plants (Table 1; Appendix B).

\section{Effect on seed production}

In the BACI experimental plot, $25.8 \%$ of the seeds produced before management (i.e., year 0 ) were alien (Table 1), although this figure probably underestimates the level of invasion, as many aliens in the understory produce few seeds due to shading (particularly Hedychium gardneranum). In the CI design, the level of invasion varied among pairs but not between plots of the same pair; $61 \%$ (range, 3-98\%) of the seeds in the unmanipulated plots were alien. In both designs native plants responded positively to the removal of alien plants by increasing seed production. Thus in the BACI unmanipulated plot the number of native seeds remained stable over the three years, while in the 

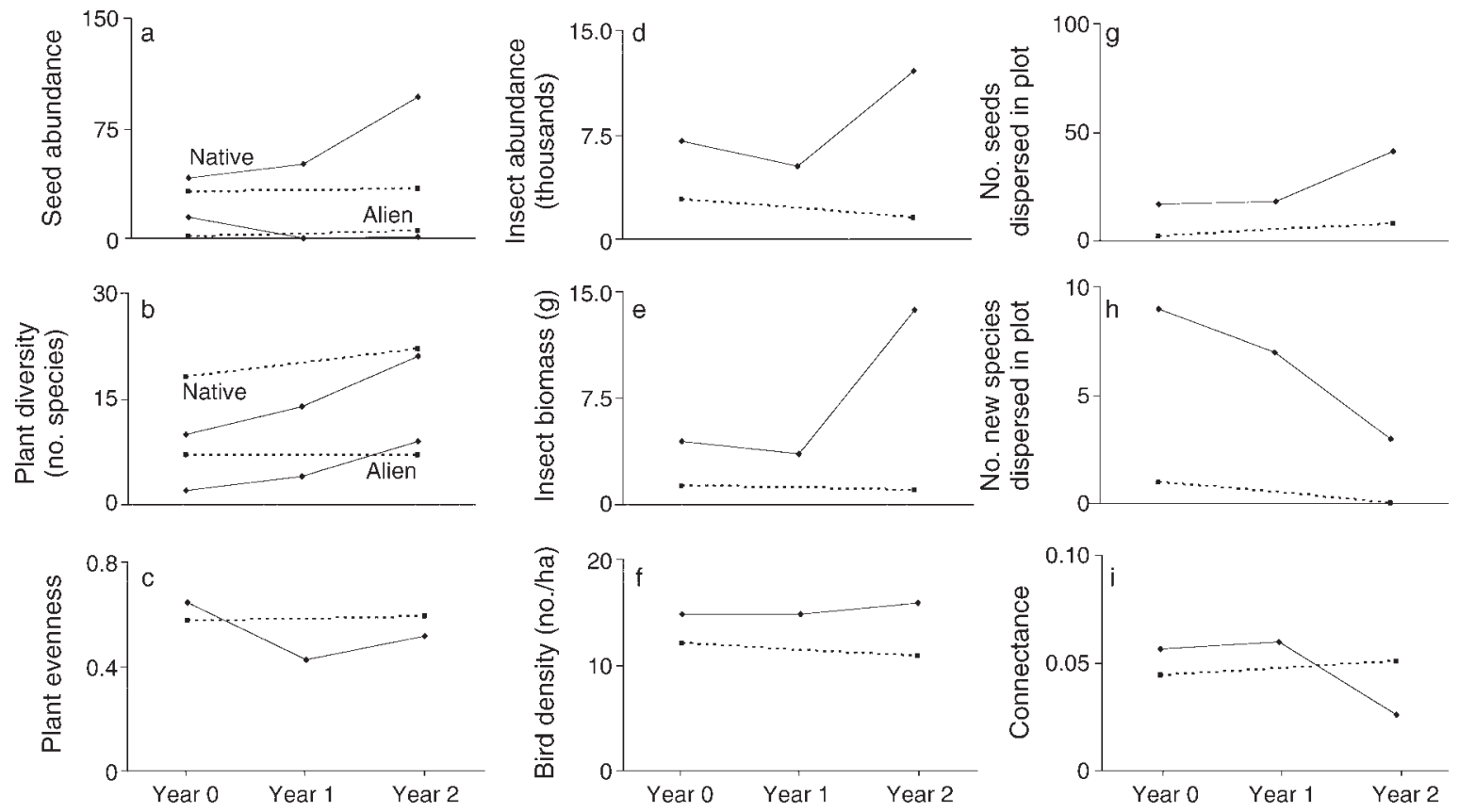

FIG. 1. Response of community descriptors between the two plots (1 ha) under the before-after control-impact (BACI) design. Solid lines represent the experimental plot, where alien plants have been removed after year 0 . Dotted lines represent the unmanipulated plot that was maintained as a control throughout the three years. The $x$-axis represents time (year 0 , year 1, year 2), and the $y$-axis represents absolute units. Evenness reflects the relative apportionment of abundances among species. Connectance is the proportion of possible links that are realized.

experimental plot it increased by $24 \%$ in year 1 and by $134 \%$ in year 2 (Fig. 1a). In year 1, native seed production in the CI experimental plots was on average $34 \%$ higher than in the unmanipulated plots, although this difference was not significant due to the high variability of the response (Fig. 2a). However in year 2, the number of Ilex perado fruits (our focal species) was $159 \%$ higher in restored than in unmanipulated plots, a highly significant difference $\left(F_{1,8}=\right.$ 16.82, $P=0.003$ ).

Native species diversity decreased with management in the CI design $\left(F_{1,4}=8.00, P=0.047\right)$ as four native species, Carex viridula, Luzula purpureosplendens, Frangula azorica, and Picconia azorica, were lost from the alien removal plots, probably due to the weeding disturbance. However in the BACI design, management increased native diversity by $40 \%$ in year 1 and by $110 \%$ in year 2 (Fig. 1b). Similarly, plant evenness was affected in opposite directions in the two experiments; evenness increased in the CI design (Fig. 2a) but decreased in the BACI experiment in year 1, with a slight increase in year 2 (Fig. 1c).

\section{Effect on seed consumers}

Herbivorous insects and their parasitoids increased in abundance and biomass in both experiments, and birds increased in density, after alien removal. In the BACI design, insect abundance and insect biomass followed closely the pattern of native seed production, i.e., relatively stable or with a small decline in year 1 and a large increase in year 2 (70\% insect abundance; $210 \%$ insect biomass; Fig. 1d, e). Bird density (BACI design only) had a similar pattern (stable in year 1, increase in year 2); however the magnitude of the increase in density in the second year (7\%) was considerably smaller than that of insects (70\%) (Fig. If vs. Fig. 1d). In the CI design there was an overall $244 \%$ increase in insect abundance, although the magnitude of the response was very variable between paired plots (Fig. 2b). This, along with the small sample size (five pairs), may explain the lack of statistical significance $\left(F_{1,4}=1.65, P=0.27\right)$.

\section{Effect on seed dispersal}

A total of 436 droppings from nine bird species were collected and analyzed. While the total number of entire seeds found in bird droppings increased by $55 \%$ over the course of the three years of the BACI design (Fig. 1g), the number of dispersed species decreased, particularly those of native species. Furthermore, over the course of the three years, the number of alien seeds dispersed increased by $141 \%$ (almost entirely due to dispersal of Leicesteria formosa), while the number of dispersed native seeds increased by only $12 \%$. The number of new seed species dispersed into the plots decreased (Fig. 1h) as the diversity of adult plants in the plots increased (Fig. 1b).

\section{Effect on network structure}

Both experimental designs revealed that plants, herbivores, parasitoids, and birds are linked together 

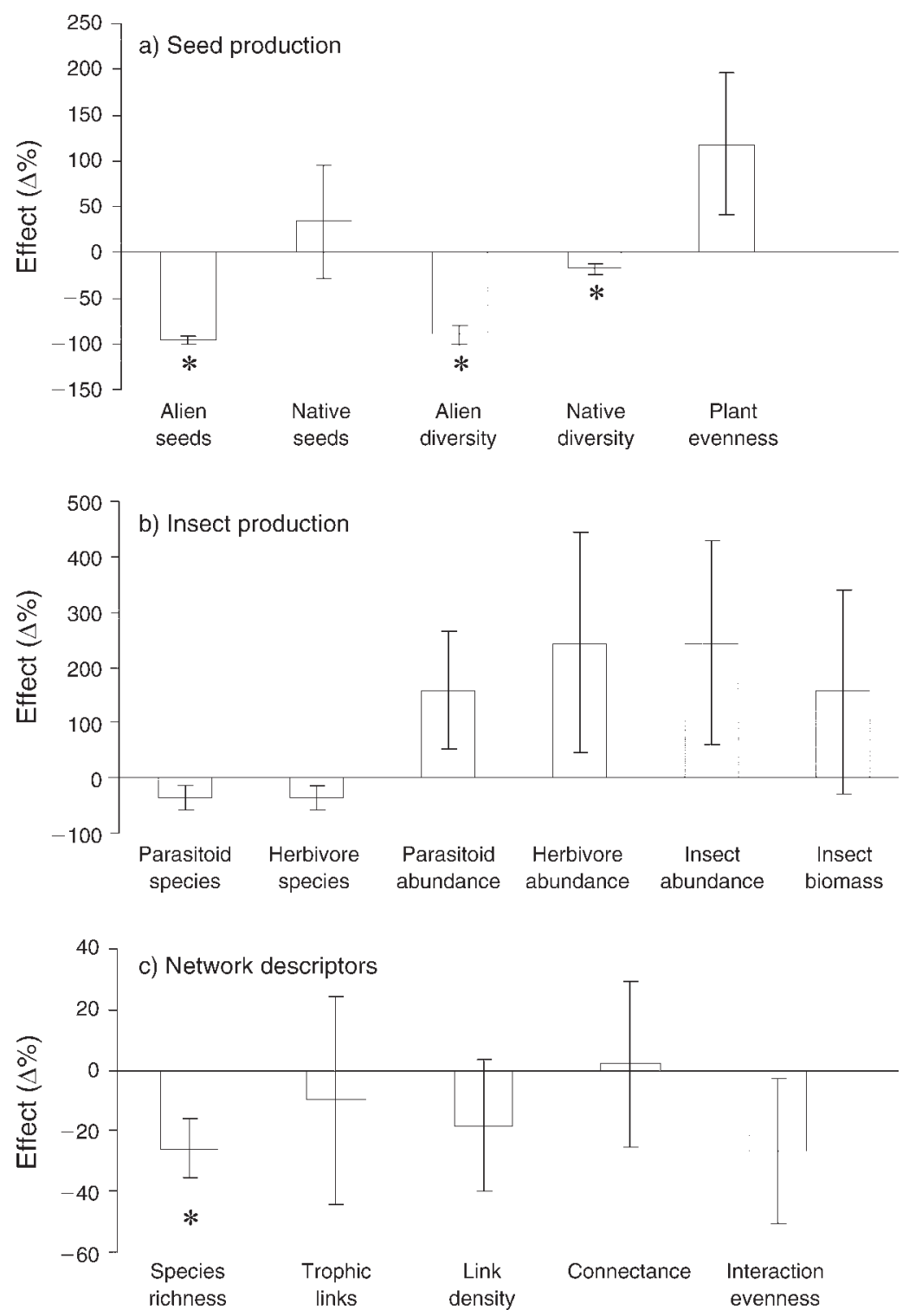

FIG. 2. Magnitude of the effect of alien plant removal on the experimental plots under the control-impact (CI) design. Bars represent the effect (percentage of variation in relation to the paired control site) on different biodiversity and network descriptors (mean $\pm \mathrm{SE}$ ). For example, in panel (a), seed production is negatively affected nearly $100 \%$ by alien seed abundance in restoration vs. control plots. Alien and native seeds represent alien and native seed abundance, respectively. Link density reflects the average number of links per species. Interaction evenness measures the uniformity of link distribution. Connectance is the proportion of possible links that are realized. Significant results for $\alpha<0.05$ are indicated with an asterisk.

in complex networks of interactions. The webs from the BACI design (Fig. 3) quantified 81 unique interactions between 39 plant species, 17 insect herbivores, six parasitoids, and nine birds. The webs from the CI design quantified 19 unique interactions between 20 plant species, 14 herbivores, and two parasitoids (Appendices B and C). In the BACI design, link density and connectance increased in the unmanipulated plot over the three years and in the experimental plot from year 0 to year 1 , but were considerably reduced in year 2 (Table 1; Fig. 1i). In the CI design, the only network descriptor that was significantly affected by restoration was the total number of species (network size: $F_{1,4}=$ 9.59, $P=0.036$ ). All other variables, i.e., number of links, link density, connectance, and interaction evenness, were highly variable among plots of the CI design as seen by the large error bars in Fig. 2c.

\section{Effect on seedling survival and growth}

Of the 270 seedlings planted, $77 \%$ survived the first year, with a predictable significant effect of "species" in the survival probability; i.e., some species survive better than others (Wald statistics $=20.8, \mathrm{df}=7, P=0.004$ ). While survival rate was higher for alien than for native 

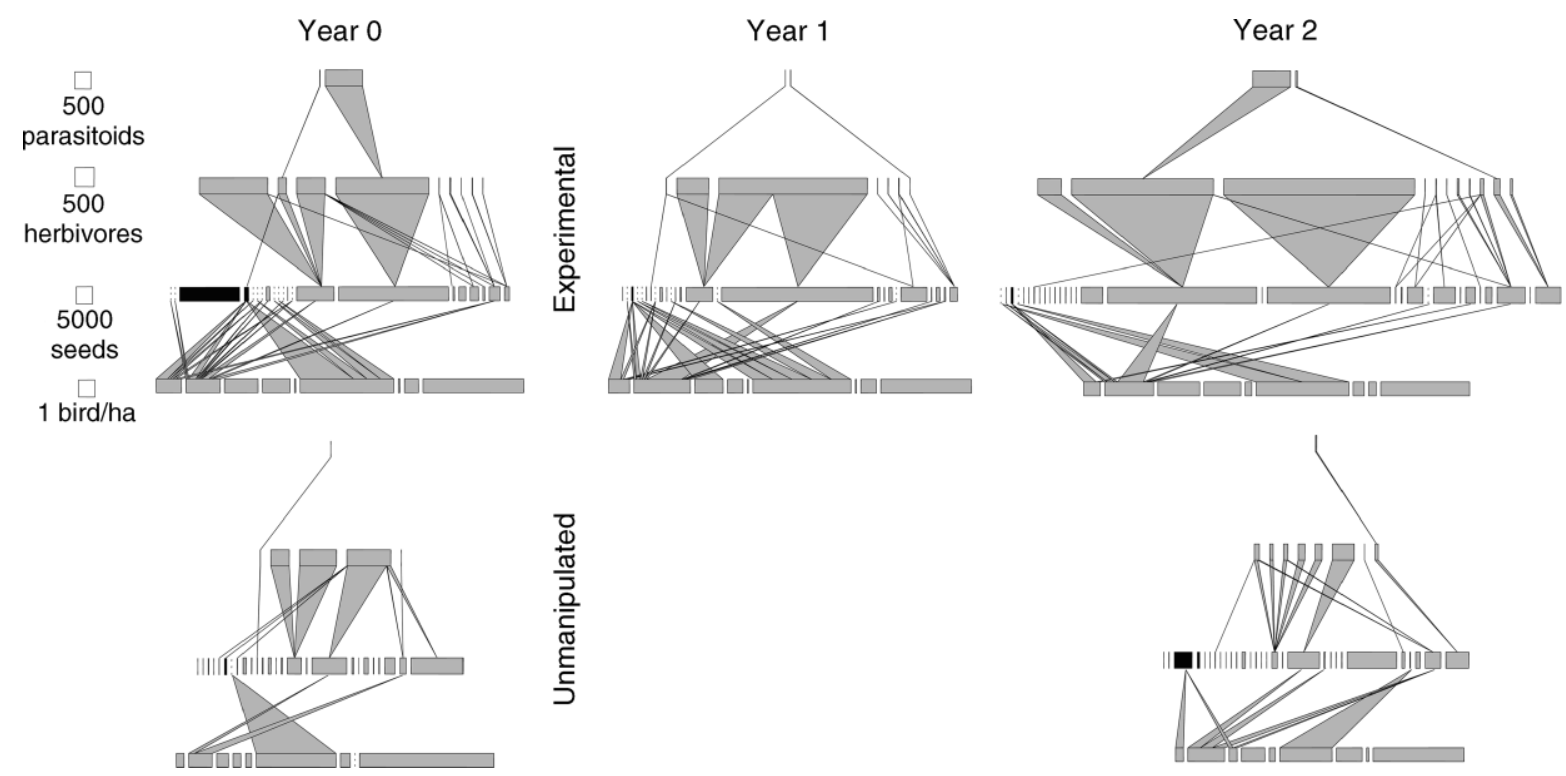

FIG. 3. Quantified food webs from the two plots (1 ha) under the before-after control-impact (BACI) design. In the experimental plot alien plants have been removed after year 0 . The unmanipulated plot was maintained as a control throughout the three years. Each horizontal bar represents a species, and its width represents its relative abundance according to the scale represented by the open squares (top left); the same scale applies to all panels. For example, if one gray bar on the bottom level of any panel is 1.5 times wider than the bottom open square, then that bird species has an abundance of 1.5 birds/ha. The area of the triangles connecting each level represents the frequency of the interaction (note that rare interactions resemble a line more than a triangle). All the parasitoids are linked to one herbivore, and each herbivore has an interaction with one plant; thus the number of interactions equals the number of individuals in the "predator" row. The order of the four trophic levels is the same in the five panels: birds, seeds, herbivores, and parasitoids (from the bottom up). Native plants are in gray and exotic plants in black. Dotted lines represent species not detected as adult plants inside the plot whose seeds were being dispersed by birds to the plot.

seedlings, and higher on restored than in the unmanipulated plots, neither effect was statistically significant (Fig. 4a). The surviving seedlings in the experimental plots grew significantly taller than those in unmanipulated plots $\left(F_{1,193}=10.47, P<0.001\right.$; Fig. $\left.4 b\right)$. On average, alien seedlings grew more than natives, but again this effect was not significant $\left(F_{1,193}=0.05, P=\right.$ 0.828; Fig. 4b). However, there was a significant interaction between these two variables, status (alien/ native) and treatment (restored/control) $\left(F_{1,193}=4.48, P\right.$ $=0.036$ ), indicating that the removal of alien plants significantly increased the growth of alien seedlings but not that of natives (Fig. 4b).

\section{Discussion}

In both experimental designs the removal of alien plants was followed by a positive cascade through the community: native plants increased their seed output, herbivore abundance and biomass increased, and parasitoid abundance increased as did bird density. In this section we outline the limitations of our approach and discuss the implications of our results for this particular restoration program and, more broadly, for the field of ecological restoration.

\section{Limitations}

Both experimental designs have limitations; an ideal design would be a before-after control-impact paired- series (BACIPS), where several replicates of control and restored sites would be followed for several years before and after management (Osenberg et al. 2006). However, such a design is rarely possible within restoration studies (Osenberg et al. 2006). In our case, the combination of the BACI and CI designs was the best alternative available within the ongoing restoration program, which allowed us to consider both spatial and temporal variability. For logistical, legal, and ethical reasons, it was not possible to have a disturbance control plot, as this would have involved disturbing the last remaining area of native vegetation on the island. Such a plot would, however, have benefited the study, allowing us to test that the responses observed here are a consequence of alien plant removal and not a disturbance effect.

\section{Effect of alien removal on seed production}

The number of native seeds increased considerably after management in both experiments. The results from the BACI design show that native plants may need time (in this case one year) to translate the release from competition into an increase in the number of seeds produced. However, the twofold increase in native species richness and seed abundance in year 2 indicates that restoration is on the desired trajectory. The results are similar in the CI experiment, with a mixed response from native plants in the first year but a clear response 
from the focal tree, Ilex perado, within the weeded plots in the second year.

In the $\mathrm{CI}$ design, but not in the BACI design, native seed diversity was significantly lower in restored than in unmanipulated plots, most likely as a result of the disturbance associated with weeding. Some trampling or accidental poisoning of native plants is unavoidable, particularly when the initial level of invasion is high (as in some pairs of the CI design). This may explain the loss of two endemic annual grasses, Carex viridula and Luzula purpureosplendens, from the alien removal plots, although both species were naturally reinstated in these plots in year 2 (personal observation). Two endemic tree species present in the experimental plots, Frangula azorica and Picconia azorica, did not produce fruits. These species flower early in the season (Schäffer 2002) and presumably did not have enough time to respond to any likely increase in resources following the removal of alien plant species.

The differing effects of management on species evenness were probably a consequence of the different invasion levels of the two experiments. While in the BACI study the removal of common exotics reduced the number of dominant species (decreasing evenness), the highly invaded plots within the CI study saw an increase in evenness among the poorly represented native plants following the removal of the two dominant species.

\section{Effect of alien removal on seed consumers}

In the BACI design, insect abundance and biomass closely followed the increase in native seed production. This result suggests that once the hosts (native seeds) are reinstated, the insects respond relatively quickly and increase in abundance accordingly. In the CI design, alien removal plots produced three times more insects than unmanipulated plots (mean, 733 and 221 insects on the restored and unmanipulated plots, respectively), although this difference was not significant due to the high variability in the response (Fig. 2b). It is important to point out that the restoration of the insect community was noticeably weaker in the most invaded plots of the CI design; for example no insects emerged from the seeds collected on the experimental plot of the most invaded pair, where $98 \%$ of all seeds were alien (Appendix D). Taken altogether, these results support the view that while restoration is possible and relatively easy on moderate levels of disturbance (in this case invasion), it can be extremely difficult once this restoration threshold is crossed (Hobbs and Harris 2001).

Bird density decreased slightly from year 0 to year 2 in the BACI unmanipulated plot; in contrast the bird density in the experimental plot remained constant in the first year after weeding (as did the number of native seeds), but increased in year 2 following the twofold increase in the production of native seeds. In the experimental plot, the density of the Azores Bullfinch increased by one order of magnitude from 0.05 birds/ha
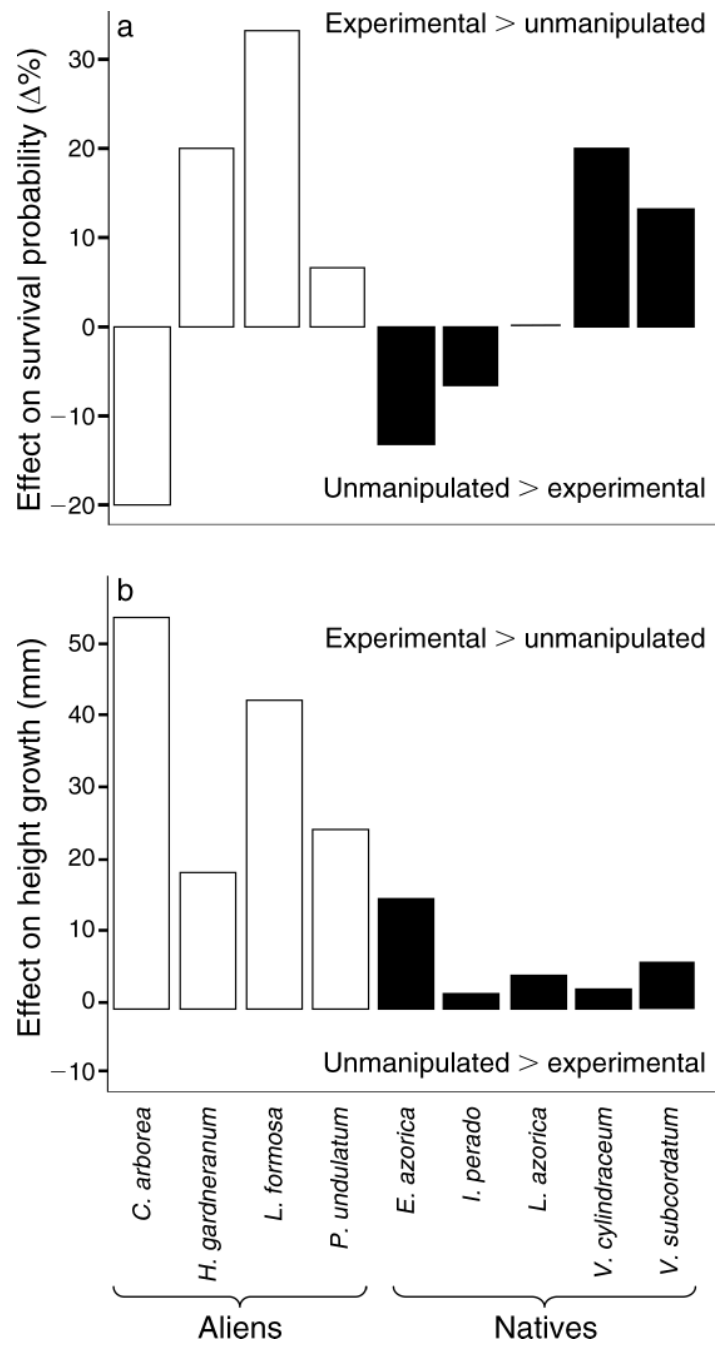

FIG. 4. Effect of restoration on the survival and growth of native and alien seedlings. The bars represent, within each species, the effect of restoration (experimental plots) vs. control (unmanipulated plots) on survival and growth. Positive values indicate higher survival or growth for plants in experimental (restored) plots; negative values indicate higher survival or growth of plants in unmanipulated plots. Species are Clethra arborea, Hedychium gardneranum, Leicesteria formosa, Pittosporum undulatum, Erica azorica, Ilex perado, Lysimachia azorica, Vaccinium cylindraceum, and Viburnum subcordatum.

in year 1 to 0.5 birds/ha in year 2; no change was seen in the unmanipulated plot. This was the greatest increase of all the bird species and was probably a direct consequence of the increase in native seed abundance (particularly I. perado and Vaccinium cylindraceum) given the strict association of the Azores Bullfinch with the native laurel forest (Ramos 1996). Thus in addition to the positive community-level responses to habitat management reported here, there was a tenfold increase in the focal species that originally motivated the restoration program. 


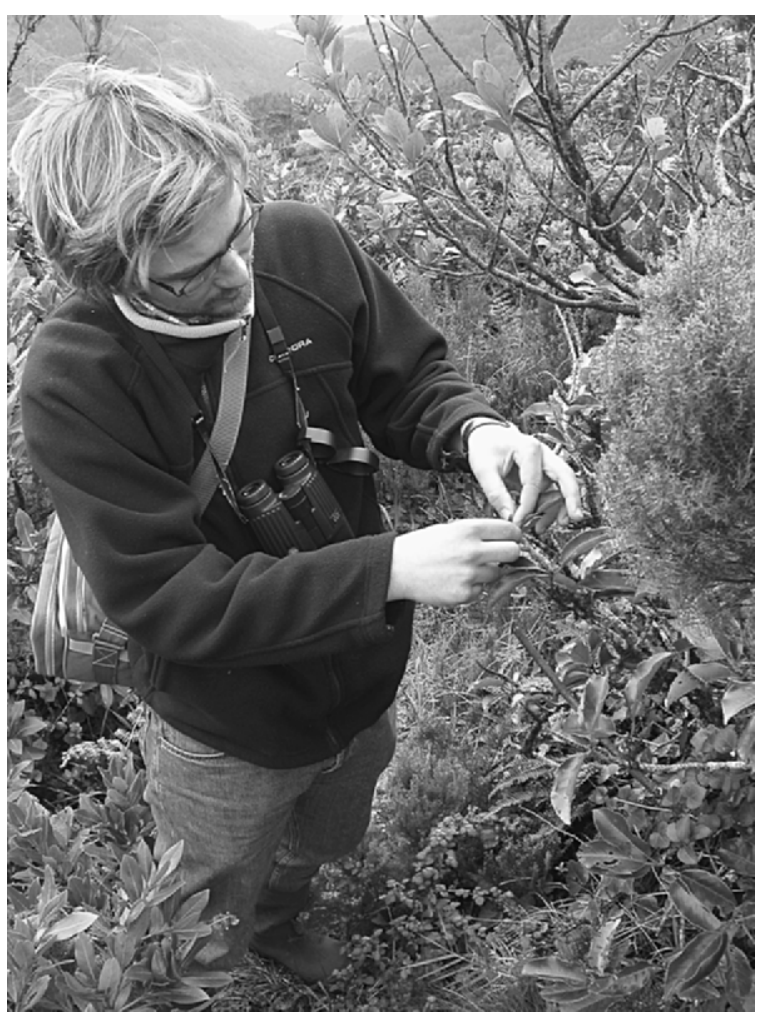

Plate 1. Along transects, all ripe seeds and fruits (hereafter collectively referred to as seeds) within $1 \mathrm{~m}$ of the transect line were collected from the plants, identified, and counted. Photo credit: J. Memmott.

Although the increase in insect abundance after management was much larger than the effect on birds ( $70 \%$ vs. $7 \%$, respectively), these effects are not directly comparable given that birds have much slower generation times. Moreover, birds are trophic generalists in comparison with many insect herbivores (Sallabanks and Courtney 1992), and alien seeds are much more likely to provide a suitable food source for birds than for insects.

\section{Effect of alien removal on seed dispersal}

The restoration of ecosystem function (in this case seed dispersal) is crucial for the long-term stability of restored communities (Handel 1997), particularly in a scenario of plant invasion (Gosper et al. 2005, Buckley et al. 2006). Our study frames bird-dispersed invasive plants in a more realistic situation, that of multiple plants and multiple dispersers, rather than the traditional focus on pairwise interactions. Birds were resilient to the removal of alien plants, a positive factor given that poor seed dispersal is often a limiting factor in forest recovery (Holl et al. 2000, White et al. 2004) and that birds are typically the main seed dispersers in many systems (Herrera 1995). Whether seed dispersal will be beneficial or detrimental to forest recovery ultimately depends on whether birds are dispersing native or alien seeds. Our results indicate that birds disperse a higher number of native seed species but that alien seeds dominate the dispersal network in terms of seed abundance. Among seed species being dispersed into the experimental plot we found Pittosporum undulatum, Clethra arborea, and Cryptomeria japonica, three species that are among the most problematic invaders in the Azores. The role of birds as dispersers of native and alien seeds into restored sites deserves more attention as, in addition to being drivers of ecological restoration, they can also facilitate plant invasion (Gosper et al. 2005).

\section{Effect of alien removal on the network structure}

In both the BACI and the CI designs there was no clear effect of restoration on network structure. The fact that none of the network descriptors were significantly affected despite the elimination of a substantial proportion of all seeds is an encouraging result. This result indicates the importance of native species in structuring the community and suggests that network structure and therefore probably its robustness (Dunne et al. 2002) were not significantly affected by the removal of alien plant species. Spatial variability and initial species composition strongly influenced network descriptors, making any consistent patterns difficult to detect with small sample sizes.

\section{Effect of alien removal on seedling survival and growth}

On average, invasive species had higher survival rates and grew faster than natives in both treatments. This suggests that for the species we studied, aliens tend to have better performances than natives for important fitness-related traits and therefore they have the potential to outcompete native vegetation. Since only alien plants grew significantly faster in the weeded plots, our results provide support to the idea that invasive plants might not have a permanent competitive advantage over co-occurring natives (Daehler 2003, Seabloom et al. 2003) but that they are particularly effective at taking advantage of available resources (Daehler 2003, Lockwood et al. 2007).

The significant interaction between plant status (alien/ native) and treatment (restored/control) indicates that even if management improves the growth of alien and native plants, the effect is greater for aliens. In this sense our results support the view that alien plant removal is in itself a form of disturbance (Gerhardt and Collinge 2003) that benefits the performance of aliens over that of co-occurring natives (Mack et al. 2000). It has been suggested that ultimately this can lead to the competitive exclusion of native plant recruitment, leading to a situation close to the original with an ensuing waste of economic resources (D'Antonio and Meyerson 2002, Lake and Leishman 2004, Buckley 2008). However, it is important to note that in this study, all alien seedlings were transplanted from adjacent areas to the experi- 
mental and unmanipulated plots, and that natural regeneration of aliens was not detected in any treated plot (personal observation). Our results suggest that the effectiveness of a restoration program will ultimately be determined by the speed at which native vegetation can recover, utilize most available resources, and reduce the competitive advantage of alien plants on disturbed (resource-rich) environments, i.e., to "restore invasion resistance" (D'Antonio and Chambers 2006, Buckley 2008). In this sense, management activities aiming at accelerating native plant recovery (e.g., sowing restored areas), may prove rather important in managing the success of the restoration.

\section{Concluding Remarks and Management Implications}

The physical scale of some of the sampling plots described in this study is greater than the majority of the restoration studies (BACI design, 1 ha; other studies, usually $<100 \mathrm{~m}^{2}$; Osenberg et al. 2006). This scale of sampling was only possible by cooperation with the ongoing restoration project, and provided an alternative to the "cage effects" of small-scale experiments (Osenberg et al. 2006, Vander Zanden et al. 2006). This collaboration can prove mutually beneficial in ways other than simply providing scientific direction; for example, native seeds collected during this study and not attacked by herbivores $(\sim 50000)$ were used in the restoration program to sow areas cleared of weeds.

An important outcome from this study is the fact that monitoring schemes that evaluate restoration for periods of less than two years may miss important signs of recovery. Here in both designs there was little change following the removal of alien plants during the first year, while in the second year, restoration was clearly on the right trajectory. For example, seed and insect abundance increased in the second year in the BACI design, and seed production of holly increased in the second year of the CI design. The fact that in the BACI design the proportion of alien seeds decreased between year 1 and year 2 indicates that native plants were recovering faster than aliens. However, whether this recovery is only temporary (i.e., the result of a rapid response from adult native plants), or if natives will succeed in restoring invasion resistance, can only be determined by further monitoring. This study highlights three aspects that may prove critical for the success of restoration projects. First, seed dispersal may positively or negatively affect restoration depending on whether native or alien seeds are preferentially dispersed. Second, the disturbance caused by the eradication of alien plants may enhance the performance of alien over native seedlings, highlighting the need to control alien seedling germination following the initial eradication. Third, understanding the nature of frugivore-dispersed invasive plants might prove critical when deciding upon management plans (Buckley et al. 2006).
In summary, we have demonstrated that the positive effects of alien plant removal can cascade upward through the food web and benefit multiple trophic levels. Our study reinforces the view that structural and functional approaches can be used together when evaluating ecological restoration, and that food webs can provide a powerful tool for this more holistic approach, with benefits for both restoration science and restoration practice.

\section{ACKNOWLEDGMENTS}

We thank J. Deeming, B. Merz, O. Karsholt, K. Hortsman, K. van Achterberg, and P. Borges for the insect identifications; the LIFE-Priolo team for help with field work; K. Henson, M. Pocock, and M. Devoto for commenting on the manuscript; and Fundação para a Ciência e a Tecnologia (Portugal) for funding Ruben Heleno.

\section{Literature Cited}

Bersier, L. F., C. Banasek-Richter, and M. F. Cattin. 2002. Quantitative descriptors of food-web matrices. Ecology 83: 2394-2407.

Bersier, L. F., and G. Sugihara. 1997. Scaling regions for food web properties. Proceedings of the National Academy of Sciences (USA) 94:1247-1251.

Bibby, C. J., N. D. Burgess, D. A. Hill, and S. Mustoe. 2000. Bird census techniques Second edition. Academic Press, London, UK.

Borges, P., R. Cunha, R. Gabriel, A. F. Martins, L. Silva, and V. Vieira. 2005. A list of the terrestrial fauna (Mollusca and Arthropoda) and flora (Briophyta, Pteridophyta and Spermatophyta) from the Azores Direcção Regional do Ambiente. Universidade dos Açores, Horta, Angra do Heroismo, Ponta Delgada, Azores.

Buckley, Y. M. 2008. The role of research for integrated management of invasive species, invaded landscapes and communities. Journal of Applied Ecology 45:397-402.

Buckley, Y. M., et al. 2006. Management of plant invasions mediated by frugivore interactions. Journal of Applied Ecology 43:848-857.

Ceia, R., R. Heleno, and J. Ramos. 2009. Summer abundance and ecological distribution of passerines in native and exotic forests in São Miguel, Azores. Ardeola 56:25-39.

Daehler, C. C. 2003. Performance comparisons of co-occurring native and alien invasive plants: implications for conservation and restoration. Annual Review of Ecology, Evolution, and Systematics 34:183-211.

D'Antonio, C. M., and J. C. Chambers. 2006. Using ecological theory to manage or restore ecosystems affected by invasive plant species. Pages 260-279 in D. A. Falk, M. A. Palmer, and L. Zedler, editors. Foundations of restoration ecology. Island Press, Washington, D.C., USA.

D'Antonio, C., and L. A. Meyerson. 2002. Exotic plant species as problems and solutions in ecological restoration: a synthesis. Restoration Ecology 10:703-713.

Davis, M. A., J. P. Grime, and K. Thompson. 2000. Fluctuating resources in plant communities: a general theory of invasibility. Journal of Ecology 88:528-534.

Dunne, J. A., R. J. Williams, and N. D. Martinez. 2002. Network structure and biodiversity loss in food webs: robustness increases with connectance. Ecology Letters 5: $558-567$.

Dunne, J. A., R. J. Williams, and N. D. Martinez. 2004. Network structure and robustness of marine food webs. Marine Ecology Progress Series 273:291-302.

Dytham, C. 2003. Choosing and using statistics: a biologist's guide. Second edition. Blackwell Publishing, Malden, Massachusetts, USA. 
Forup, M. L., K. S. E. Henson, P. G. Craze, and J. Memmott. 2008. The restoration of ecological interactions: plantpollinator networks on ancient and restored heathlands. Journal of Applied Ecology 45:742-752.

Gerhardt, F., and S. K. Collinge. 2003. Exotic plant invasions of vernal pools in the Central Valley of California, USA. Journal of Biogeography 30:1043-1052.

Gosper, C. R., C. D. Stansbury, and G. Vivian-Smith. 2005. Seed dispersal of fleshy-fruited invasive plants by birds: contributing factors and management options. Diversity and Distributions 11:549-558.

Grafen, A., and R. Hails. 2002. Modern statistics for the life sciences. Oxford University Press, Oxford, UK.

Haggar, J. P. 1988. The structure, composition and status of the cloud forests of Pico Island in the Azores. Biological Conservation 46:7-22.

Handel, S. N. 1997. The role of plant-animal mutualisms in the design and restoration of natural communities. Cambridge University Press, Cambridge, UK.

Heleno, R. H., R. S. Ceia, J. A. Ramos, and J. Memmott. 2009. The effect of alien plants on insect abundance and biomass: a food web approach. Conservation Biology 23:410-419.

Henneman, M. L., and J. Memmott. 2001. Infiltration of a Hawaiian community by introduced biological control agents. Science 293:1314-1316.

Henson, K. S. E. 2007. The restoration of ecological interactions. Ph.D. thesis. University of Bristol, Bristol, UK.

Herrera, C. M. 1995. Plant-vertebrate seed dispersal systems in the mediterranean: ecological, evolutionary, and historical determinants. Annual Review of Ecology and Systematics 26: 705-727.

Hobbs, R. J., and J. A. Harris. 2001. Restoration ecology: repairing the Earth's ecosystems in the new millennium. Restoration Ecology 9:239-246.

Holl, K. D., M. E. Loik, E. H. V. Lin, and I. A. Samuels. 2000. Tropical montane forest restoration in Costa Rica: overcoming barriers to dispersal and establishment. Restoration Ecology 8:339-349.

IUCN. 2000. Chiroptera specialist group, Nyctalus azoreum. The World Conservation Union (IUCN), 2007 Red List of Threatened Species. 〈www.iucnredlist.org

IUCN. 2005. BirdLife International, Pyrrhula murina. The World Conservation Union (IUCN), 2007 Red List of Threatened Species. 〈www.iucnredlist.org〉

Keane, R. M., and M. J. Crawley. 2002. Exotic plant invasions and the enemy release hypothesis. Trends in Ecology and Evolution 17:164-170.

Lake, J. C., and M. R. Leishman. 2004. Invasion success of exotic plants in natural ecosystems: the role of disturbance, plant attributes and freedom from herbivores. Biological Conservation 117:215-226.

Lockwood, J. L., M. F. Hoopes, and M. P. Marchetti. 2007. Invasion ecology. Blackwell Publishing, Oxford, UK.

Lopezaraiza-Mikel, M. E., R. B. Hayes, M. R. Whalley, and J. Memmott. 2007. The impact of an alien plant on a native plant pollinator network: an experimental approach. Ecology Letters 10:539-550.

MacArthur, R. 1972. Geographical ecology: patterns in the distribution of species. Harper and Row, New York, New York, USA.

Mack, R. N., D. Simberloff, W. M. Lonsdale, H. Evans, M. Clout, and F. A. Bazzaz. 2000. Biotic invasions: causes, epidemiology, global consequences, and control. Ecological Applications 10:689-710.

Menninger, H. L., and M. A. Palmer. 2006. Restoring ecological communities: from theory to practice. Pages 88112 in D. A. Falk, M. A. Palmer, and L. Zedler, editors, Foundations of restoration ecology. Island Press, Washington, D.C., USA.

Osenberg, C. W., B. M. Bolker, J. S. White, C. M. St. Mary, and J. S. Shima. 2006. Statistical issues and study design in ecological restorations: lessons learned from marine reserves. Pages 280-302 in D. A. Falk, M. A. Palmer, and L. Zedler, editors. Foundations of restoration ecology. Island Press, Washington, D.C., USA.

Palmer, M. A., R. F. Ambrose, and N. L. Poff. 1997. Ecological theory and community restoration ecology. Restoration Ecology 5:291-300.

Ramos, J. A. 1995. The diet of the Azores Bullfinch Pyrrhula murina and the floristic variation within its range. Biological Conservation 71:237-249.

Ramos, J. A. 1996. Introduction of exotic tree species as a threat to the Azores Bullfinch population. Journal of Applied Ecology 33:710-722.

Sallabanks, R., and S. P. Courtney. 1992. Frugivory, seed predation, and insect-vertebrate interactions. Annual Review of Entomology 37:377-400.

Sample, B. E., R. J. Cooper, R. D. Greer, and R. C. Whitmore. 1993. Estimation of insect biomass by length and width. American Midland Naturalist 129:234-240.

Schäffer, H. 2002. Flora of the Azores: a field guide. Margraf Verlag, Weikersheim, Germany.

Scheiman, D. M., E. K. Bollinger, and D. H. Johnson. 2003. Effects of leafy spurge infestation on grassland birds. The Journal of Wildlife Management 67:115-121.

Seabloom, E. W., W. S. Harpole, O. J. Reichman, and D. Tilman. 2003. Invasion, competitive dominance, and resource use by exotic and native California grassland species. Proceedings of the National Academy of Sciences (USA) 100:13384-13389.

Shea, K., and P. Chesson. 2002. Community ecology theory as a framework for biological invasions. Trends in Ecology and Evolution 17:170-176.

Silva, L. D. 2001. Plantas vasculares invasoras no Arquipélago dos Açores. Ph.D. thesis. University of the Azores, Ponta Delgada, Azores.

Silva, L., and C. W. Smith. 2006. A quantitative approach to the study of non-indigenous plants: An example from the Azores Archipelago. Biodiversity and Conservation 15:16611679.

Simberloff, D. 2004. Community ecology: Is it time to move on? American Naturalist 163:787-799.

Sugihara, G., K. Schoenly, and A. Trombla. 1989. Scale invariance in food web properties. Science 245:48-52.

Temperton, V. M., R. J. Hobbs, T. Nuttle, and S. Halle, editors. 2004. Assembly rules and restoration ecology: Bridging the gap between theory and practice. Island Press, Washington, D.C., USA.

Traveset, A., and D. M. Richardson. 2006. Biological invasions as disruptors of plant reproductive mutualisms. Trends in Ecology and Evolution 21:208-216.

Tutin, T. G. 1953. The vegetation of the Azores. The Journal of Ecology 41:53-61.

Tylianakis, J. M., T. Tscharntke, and O. T. Lewis. 2007. Habitat modification alters the structure of tropical hostparasitoid food webs. Nature 445:202-205.

Vander Zanden, M. J., J. D. Olden, and J. B. Zedler. 2006. Food-web approaches in restoration ecology. Pages 165-189 in D. A. Falk, M. A. Palmer, and L. Zedler, editors. Foundations of restoration ecology. Island Press, Washington, D.C., USA.

Vitousek, P. M., L. R. Walker, L. D. Whiteaker, D. Muellerdombois, and P. A. Matson. 1987. Biological invasion by Myrica faya alters ecosystem development in Hawaii. Science 238:802-804.

Wang, B. C., and T. B. Smith. 2002. Closing the seed dispersal loop. Trends in Ecology and Evolution 17:379-386.

White, E., N. Tucker, N. Meyers, and J. Wilson. 2004. Seed dispersal to revegetated isolated rainforest patches in North Queensland. Forest Ecology and Management 192:409426 . 
Wilcove, D. S., D. Rothstein, J. Dubow, A. Phillips, and E. Losos. 1998. Quantifying threats to imperiled species in the United States. Bioscience 48:607-615.

Wolfram Research. 1999. Mathematica. Version 4.0. Wolfram Research, Champaign, Illinois, USA.
Woods, K. D. 1993. Effects of invasion by Lonicera tatarica L. on herbs and tree seedlings in four New England forests. American Midland Naturalist 130:62-74.

Zar, J. H. 1999. Biostatistical analysis. Fourth edition. Pearson Prentice Hall, Upper Saddle River, New Jersey, USA.

\section{APPENDIX A}

Mean monthly temperature and precipitation for the island of São Miguel, Azores (Ecological Archives A020-040-A1).

\section{APPENDIX B}

Comparison of community descriptors between the control and experimental plots of each pair for the control-impact (CI) design (Ecological Archives A020-040-A2).

\section{APPENDIX C}

Species composition for control and experimental plots of the before-after control-impact (BACI) design (Ecological Archives A020-040-A3).

\section{APPENDIX D}

Species composition for control and experimental sites of the control-impact (CI) design (Ecological Archives A020-040-A4). 